\title{
Septoplasty without nasal packing: functional outcomes and complications a prospective clinical study
}

\begin{abstract}
Objective: To evaluate the functional outcomes and complications of pack free septoplasty in adults.

Subject: This study included 49 patient who underwent septoplasty randomize prospectively. Nasal obstruction was scored with the NOSE scale before the operation. Septoplasty was performed by the same surgeon. Nasal obstruction was re-scored in the $1 \mathrm{st}$ and the 3rd postoperative months. The postseptoplasty complications were recorded. The preoperative and postoperative NOSE scores were compared.

Results: 35 patients ( $71.4 \%$ ) were male and 14 patients (28.6\%) were female. The subjective rate of success in the NOSE score was determined as $81.63 \%$. There was statistically significant difference between preoperative and postoperative 1st-3rd months NOSE scores $(\mathrm{p}<0.05)$. Minor hemorrhage was observed in 17 cases $(34.7 \%)$, nasal synechiae in 3 cases $(6.1 \%)$ and flap apposition in 2 cases $(4.1 \%)$.

Conclusion: Pack free septoplasty which performed with the transseptal suture technique is effective on the treatment of septum deviation. It can be performed confidently in septum surgery.
\end{abstract}

Keywords: nasal pack, septoplasty, trans-septal suture, nasal septum
Volume 3 Issue 2 - 2015

\author{
Erkan Eski, Ismail Yilmaz \\ Department of Otolaryngology, Baskent University Zubeyde \\ Hanm, Turkey
}

Correspondence: NS Erkan Eski, Otolaryngology Department, Izmir Zubeyde Hanim Hospital, Baskent University, 637I Sk. No:34 Bostanli/Karsiyaka, Izmir-Turkey, Tel +90 2323305230 , Email eskierkan@mynet.com

Received: November 28, 2014 | Published: September 21, 2015

\section{Introduction}

Septoplasty is the third frequently application among the otorhinolaryngological surgeries. ${ }^{1}$ Traditionally, nasal splint and packing are applied to maintain homeostasis, inhibit hematoma, and prevent the displacement of bone or cartilage grafts and support septal flap following septoplasty. ${ }^{2}$ However, studies questioning the routine use of packing have been published in the recent years. In these studies, it is recommended avoiding the routine use of pack, because the risk of toxic shock and pain. ${ }^{3,4}$ Instead, pack free septoplasty which performed with transept suture is suggested as it reduces morbidity. ${ }^{5}$ Studies that compare septoplasty with and without nasal packing are available. ${ }^{3-5}$ Nevertheless, there are no adequate controlled surveys evaluating the postoperative efficiency and complications of this technique. In this study, it was aimed to evaluate the functional outcomes and complications of pack free septoplasty. The NOSE scale was used to assess the functional outcomes.

\section{Material and method}

A prospective randomized study was performed at Izmir Zubeyde Hanim Training and Research Center of Baskent University, with the support of the Research Council of the Faculty of Medicine at Baskent University and by the approval of the local ethics committee. Nasal obstruction was scored with the NOSE scale, which is a disease-specific scale prepared to evaluate nasal obstruction by the American Academy of Otolaryngology $y^{5}$ (Table 1). The cases have nasal polyps, allergic rhinitis or a systemic disease and a history of hemorrhagic diathesis, anticoagulant drug use or a previous nasal surgery were excluded. Patients that were applied with additional surgical procedures, such as rhinoplasty and concha surgery, were also excluded. Informed consent was obtained from all patients. Nasal obstruction was scored with the NOSE scale. A 50\% decrease in the NOSE score was specified as the criterion for success.

\section{Surgical procedure}

In all patients, septoplasty was performed using the Cottle's technique, under general anesthesia (sevoflurane/vecuronium bromide, thiopental sodium). Lidocaine $\mathrm{HCl} \% 1$ with $1 / 100000$ epinephrine was infiltrated bilaterally at the septum ten minutes before incision. Caudal septal incision (CSI) was made on the left side. The septum was approached by elevating the mucoperichondrium and mucoperiosteum. The cartilaginous septal parts were dissected free and mobilized by chondrotomies as required. Left anterior tunnel was combined with bilateral posterior tunnel, if required. Parts of the septum which deviated were respected. Reformed tissues were replaced to empty areas after the removed cartilage and bone parts are processed. Reification (by 3/0 vicryl, Ethicon Inc., USA) of the junction zone of cartilage and premaxilla was performed in case of the detachment of caudal septum. The CSI was closed by two septocolumellar sutures. Transseptal horizontal mattress sutures were placed using 4/0 polyglactin 910 (Rapid Vicryl, Ethicon Inc., USA), without placing any nasal packs. Three to six transseptal sutures were placed at the septum. No splint or nasal packing was applied. All the operations were performed by the same surgeon. All cases were administered with prophylactic antibiotic (cefazolin sodium 1gr.) and paracetamol $3 \times 500 \mathrm{mg}$ p.o., in the postoperative period. Nasal lavage was started the 4th postoperative hour. At 2 and 5 days postoperatively all patient underwent examination. During this examination we looked for any bleeding, septal hematoma and nasal synechiae. Daily nasal irrigation with salt water solution (a mixture of $0.9 \%$ non-iodized sodium chloride and sodium bicarbonate either purified or tap water warmed to around 98degrees F / 37degrees C) is recommended 5times daily for two weeks. Any antihistaminic, nasal steroid or topical or oral decongestant drug was not allowed for 3 months after the operation. Patients were visited at the first and the third postoperative months and nasal obstruction was re-scored using 
the NOSE scale. Preoperative and postoperative NOSE scores were compared. The complications were recorded. The Wilcox on test was used in the statistical method. When the $\mathrm{p}$ value less than 0.05 , it was regarded as significant.

\section{Results}

Forty nine cases, aged 18 to 63years (mean 37.7 years) were included in the study. Of the cases, 35 (71.4\%) were male and 14
$(28.6 \%)$ were female. The rate of success in the study was determined as $81.6 \%$. There was a statistically significant difference between preoperative and postoperative nose scores (Table 2). Minor hemorrhage was observed in 17 cases (34.7\%), nasal synechiae in 3 cases $(6.1 \%)$ and flap apposition in 2 cases $(4.08 \%)$. No major hemorrhage, septal hematoma or septal perforation was observed. The flap apposition was located in the posterior section of septum in two cases.

Table I The NOSE scoring system

\begin{tabular}{llllll}
\hline & $\begin{array}{l}\text { Not a } \\
\text { Problem }\end{array}$ & $\begin{array}{l}\text { Very Mild } \\
\text { Problem }\end{array}$ & $\begin{array}{l}\text { Moderate } \\
\text { Problem }\end{array}$ & $\begin{array}{l}\text { Fairly Bad } \\
\text { Problem }\end{array}$ & $\begin{array}{l}\text { Severe } \\
\text { Problem }\end{array}$ \\
\hline Nasal congestion or stuffiness & 0 & $\mathrm{I}$ & 2 & 3 & 4 \\
Nasal blockage or obstruction & 0 & $\mathrm{I}$ & 2 & 3 & 4 \\
Trouble breathing through my nose & 0 & $\mathrm{I}$ & 2 & 3 & 4 \\
$\begin{array}{l}\text { Trouble sleeping } \\
\text { Unable to get enough air through my nose during } \\
\text { exercise or exertion }\end{array}$ & 0 & $\mathrm{I}$ & 2 & 3 & 4 \\
\hline
\end{tabular}

Table 2 An evaluation of the cases in terms of the NOSE score

\begin{tabular}{lll}
\hline & NOSE Score & PValue \\
\hline Preoperative & $14.15 \pm 1.02$ & \\
The Ist postoperative month & $5.74 \pm 1.15$ & $0.032^{*}$ \\
The 3rd postoperative month & $4.86 \pm 2.35$ & $0.025^{*}$ \\
\hline
\end{tabular}

\section{Discussion}

Septoplasty, a surgical correction of nasal septum deviation, is the 3rd frequently applied operation in otorhinolaryngological. ${ }^{1}$ Various materials (such as pack, microcell and telfa) are used following the intranasal surgical practices like septoplasty/septorhinoplasty in order to maintain homeostasis, inhibit hematoma, prevent the displacement of bone or cartilage grafts and support the septal flap. ${ }^{2}$ The negative impacts of these materials on quality of life have been shown in previous studies..$^{4-7}$ In this study, we assessed the efficiency of pack free septoplasty by the NOSE scale. We determined the subjective rate of recovery at a satisfactory rate (\% 81.6). Nasal synechiae and flap apposition were the factors that decreased the rate of success in our study. In a study some 77 septoplasty + conchaplasty cases, Gandomi et al., ${ }^{1}$ reported this rate as $89.5 \% .{ }^{1}$ However, after septoplasty using nasal packing or splint this rate is reported as 63 to $85 \% .{ }^{8,9}$ Our results, which are in agreement with the literature, indicate that the use of postseptoplasty nasal packing does not affect the functional outcomes.

In a study some 88 cases, Awan et al., ${ }^{4}$ reported 8 (18.2\%) nasal synechiae in the group with nasal packing but no nasal synechiae in pack free group. ${ }^{4}$ In our study, nasal synechiae developed in 3 cases $(6.1 \%)$. According to these results, development of synechiae does not appear to be related to the use of nasal packing. Flap apposition might become a problem in septoplasty without nasal packing. It particularly occurs in those cases where the mucoperichondrial flap is elevated until the posterior septum. We encountered this problem in 2 cases. One case was applied with suture nasal packing again. No intervention was needed for the other case. The most important complication of pack free septoplasty is the flap apposition. Absorbable supporting materials might be required in posterior flap elevations. Awan reported the rate of minor hemorrhage as $2.3 \%$ in cases pack free septoplasty. ${ }^{4}$ In our study, we determined this rate as $34.69 \%$. This rate, which may be regarded as high, might be due to the differences in assessment, for minor hemorrhages are frequent especially postoperative first hour following operation. These hemorrhages can be controlled with minor interventions. None of our cases required nasal packing. We did not observe any major hemorrhage, septal hematoma or septal perforation. Genc et al., ${ }^{10}$ showed the similar histological effects of transept suture and nasal packing in an animal experiment. In this study, no significant difference was detected between suture and nasal packing in terms of mucosal injury, cartilage thickness and fixation of mucoperichondrium. ${ }^{10}$ Our encountering of no septum perforation any patients in our study supported the safety of the suture technique. Some absorbable materials that might be used instead of nasal packing after septoplasty have been developed. They include fibrin glue, floseal and merogel. ${ }^{11,12}$ The use of these materials in endonasal surgeries significantly reduces morbidity. ${ }^{12}$ Nevertheless, their expensiveness hinders their routine use. Absorbable materials might be used in the selected cases with the risk of flap apposition. This will both increase the rate of success of pack free septoplasty and decrease the risk of complications.

\section{Conclusion}

In this study, we presented the efficiency and complications of pack free septoplasty. In conclusion, pack free septoplasty by transept suture is a successful and safe method. Its subjective functional outcomes are satisfactory.

\section{Acknowledgments}

None.

\section{Conflicts of interest}

Author declares there atre no conflicts of interest.

\section{Funding}

None.

\section{References}

1. Gandomi B, Bayat A, Kazemei T. Outcomes of septoplasty in young adults: the Nasal Obstruction Septoplasty Effectiveness study. Am J Otolaryngol. 2010;31(3):189-192. 
2. Weber R, Hochapfel F, Draf W. Packing and stents in endonasal surgery Rhinology.2000;38(2):49-62.

3. Nunez DA, Martin FW. An evaluation of postoperative packing in nasal septal surgery. Clin Otolaryngol . 1991;16(6):549-550.

4. Awan MS, Iqbal M. Nasal packing after septoplasty: A randomized comparison of packing versus no packing in 88 patients. Ear Nose Throat . 2008;87(11):624-627.

5. Lemmens W, Lemkens P. Septal suturing following nasal septoplasty: a valid alternative for nasal packing? Acta Otorhinolaryngol Belg. 2001;55(3):215-221.

6. Harrill WC, Pillsbury HC, McGuirt WF, et al.Radiofrequency turbinate reduction: ANOSE evaluation. Laryngoscope. 2007;117(11):1912-1919.
7. Orlandi RR, Lanza DC. Is Nasal Packing Necessary Following Endoscopic Sinus Surgery? Laryngoscope. 2004;114(4):1541-1544.

8. Siegel NS, Gliklich RE, Taghizadeh F, et al.Outcomes of septoplasty. Otolaryngol Head and Neck Surg . 2000;122(2):228-232.

9. Samad I, Stevens HE, Malony A. The efficiacy of nasal septal surgery. $J$ Otolaryngol . 1992;21(2):88-91.

10. Genç E, Ergin NT, Bilezikci B. Comparison suture and nasal packing in rabbit noses. Laryngoscope. 2004;114(4):639-645.

11. Valentine R, Wormald . Nasal dressing after sinus surgery: what and why? Curr Opin in Otolaryngol Head Neck Surg. 2010;18(1):44-48.

12. Erkan AN, Cakmak O, Kocer NE, et al.Effects of fibrin glue on nasal septal tissues. Laryngoscope. 2007;117(3):491-496. 